\title{
Infección rino-sinusal por Exserohilum rostratum en un niño con leucemia mieloide aguda
}

\author{
Sinus infection caused by Exserohilum rostratum in a pediatric patient with acute \\ myeloid leukemia
}

Alejandro Kral', Kathleen Batalla², M. Elena Santolaya ${ }^{3}$, Marcela Rabello ${ }^{3}$ y Marlon Barraza ${ }^{4}$

1Programa de formación de Infectología, Facultad de Medicina, Universidad de Chile, Hospital San Borja Arriarán.
Programa de formación de Pediatría, Facultad de Medicina, Universidad de Chile, Hospital Dr. Luis Calvo Mackenna.
${ }^{3}$ Unidad de Infectología, Hospital Dr. Luis Calvo Mackenna, Departamento de Pediatría, Facultad de Medicina, Universidad de Chile.
${ }^{4}$ Unidad de Farmacia clínica, Hospital Dr. Luis Calvo Mackenna.

Los autores declaran no tener conflictos de interés en relación al trabajo.

No hubo fuentes externas de financiamiento.

Recibido: 17 de septiembre de 2019 / Aceptado: 24 de diciembre de 2019

\section{Resumen}

Los episodios de neutropenia febril son cuadros graves, que requieren un estudio etiológico exhaustivo y un inicio rápido de antimicrobianos. Dentro de los posibles microorganismos causales se encuentran los de origen fúngico, los que, dependiendo de su grado de invasión tisular, pueden llegar a presentar una alta mortalidad. Presentamos el caso de un niño con una leucemia mieloide aguda, que tras su quimioterapia de inducción, presentó un episodio de neutropenia febril, con una infección rino-sinusal por Exserohilum rostratum, hongo filamentoso que raramente se asocia a cuadros patológicos. Se inició rápidamente terapia antifúngica, lo cual, asociado a un aseo quirúrgico precoz, lograron una respuesta clínica favorable, sin complicaciones. Luego del seguimiento, y tras recibir profilaxis secundaria durante los episodios de neutropenia, no ha vuelto a presentar nuevas lesiones ni compromiso rino-sinusal.

Palabras clave: Exserohilum rostratum: enfermedad fúngica invasora; inmunocomprometido; infección rino-sinusal.

\section{Introducción}

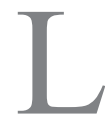

as especies del género Exserohilum corresponden a hongos filamentosos dematiáceos, ambientales, raramente asociados a cuadros patológicos. Se encuentran en el pasto y en la madera en descomposición, característicamente en climas cálidos y húmedos. Pertenecen al grupo de las feohifomicosis, al presentar elementos

\begin{abstract}
The episodes of febrile neutropenia are severe cases that require an exhaustive etiological study and a quick start of antimicrobial agents. Within the possible microorganisms, fungal origins are also found, and depending on its tissue invasion, they can reach a high mortality rate. A case of a pediatric patient who suffered from acute myeloid leukemia is reported, and after his induction chemotherapy, the patient showed an episode of febrile neutropenia, which matches a rhinosinusal infection caused by Exserohilum rostratum, a filamentous fungi that is uncommonly associated with pathological cases. An antifungal therapy and an early surgical treatment were started, which lead to a positive response, without complications to the patient. After the monitoring and receiving secondary prophylaxis during the episodes of neutropenia, the patient hasn't presented new injuries nor rhinosinusal damage.

Keywords: Exserohilum rostratum; invasive fungal disease; immunocompromised; rhinosinusal infection.
\end{abstract}

miceliales septados oscuros. Sus conidios son elipsoidales y presentan un hilio pigmentado, truncado y protruyente ${ }^{1,2}$.

Son capaces de producir infecciones predominantemente en pacientes inmunocomprometidos, atópicos o con antecedentes de trauma. Las manifestaciones clínicas pueden ser locales, cutáneas o rino-sinusal, o infecciones invasoras, estas últimas asociadas a alta mortalidad ${ }^{3}$.

En el año 2012, se reportó en E.U.A. un brote de meningitis por 
Exserohilum en pacientes usuarios de corticoesteroides inyectables ${ }^{4}$. Además de ese brote, se han reportado alrededor de 50 casos en la literatura especializada, en población adulta y pediátrica, predominantemente en India, Israel y E.U.A. ${ }^{5}$, con afectación sinusal en aproximadamente $50 \%$ de los pacientes. Si bien en Argentina se ha descrito un caso de un paciente pediátrico inmunocomprometido con afección sinusal ${ }^{6}$, a la fecha aún no hay casos reportados en nuestro país.

Presentamos el caso de un niño de 11 años con una leucemia mieloide aguda (LMA), y tras su terapia de inducción de quimioterapia presentó una lesión en mucosa nasal, que luego del estudio microbiológico y molecular, resultó compatible con una infección por Exserohilum rostratum.

\section{Caso clínico}

Escolar de sexo masculino de 11 años con antecedentes de una LMA M4 de reciente diagnóstico. Recibió quimioterapia de inducción, evolucionando al séptimo día con un episodio de neutropenia febril de alto riesgo. Recibió ocho días de tratamiento antimicrobiano con piperacilina/ tazobactam asociado a cloxacilina. Presentó una reacción adversa cutánea que se atribuyó a los $\beta$-lactámicos que motivó el uso de corticoesteroides sistémicos por cinco días y cambio de esquema antibacteriano a ciprofloxacina, completando en total diez días de tratamiento. Evolucionó con una neutropenia profunda persistente, presentando a las tres semanas post-quimioterapia un nuevo episodio febril asociado a una lesión necrótica en el tabique nasal

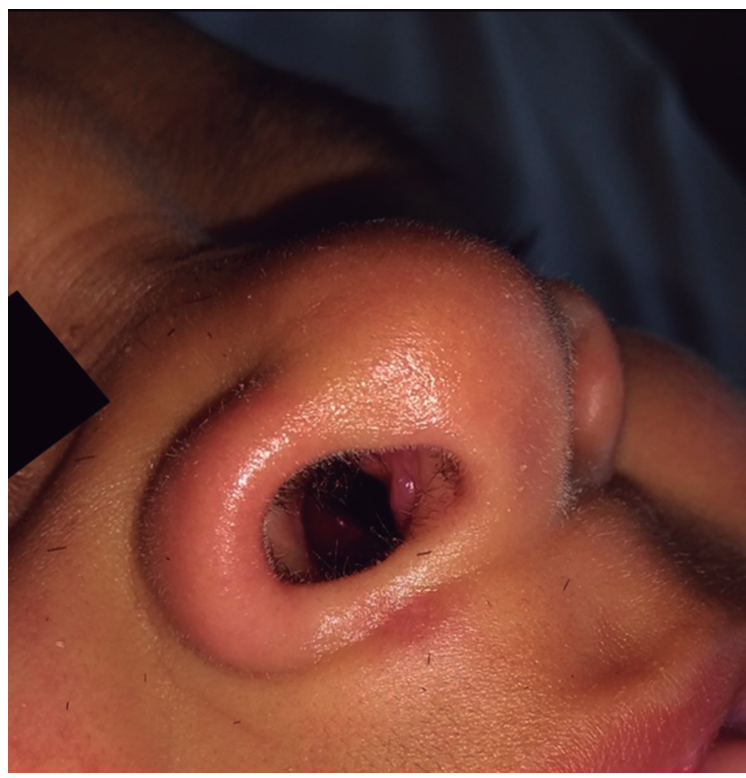

derecho no dolorosa, con una mucosa circundante con características inflamatorias, sin otra sintomatología asociada (Figura 1).

El recuento absoluto de neutrófilos (RAN) era de 0 céls $/ \mathrm{mm}^{3}$, con parámetros inflamatorios bajos: PCR 24 $\mathrm{mg} / \mathrm{L}$. Los hemocultivos fueron negativos. Se realizó una tomografía computarizada (TC) de cavidades paranasales, que mostró un leve engrosamiento de la mucosa del seno esfenoidal y celdillas etmoidales derechas, sin signos de compromiso óseo (Figura 2).

Inició tratamiento antimicrobiano con ciprofloxacina y clindamicina. Por sospecha de una enfermedad fúngica invasora (EFI), inició además anfotericina $\mathrm{B}$ liposomal en dosis de $5 \mathrm{mg} / \mathrm{kg} /$ día.

Dentro de las 24 h siguientes, se realizó una revisión endoscópica evidenciando una lesión costrosa en la región caudal de tabique nasal derecho. Se realizó un aseo quirúrgico, se resecó la costra con bordes sanos y se extrajo una muestra de biopsia de mucosa nasal para cultivo y estudio histológico.

Para descartar una EFI se complementó el estudio con la búsqueda de hifas en orina, que resultaron negativas y con una TC de tórax y ecografía abdominal que resultaron sin hallazgos patológicos. El estudio de galactomanano sérico seriado evidenció valores persistentes bajo el valor de corte de 0,5 (valor máximo 0,2 ).

El estudio histopatológico concluyó una mucosa nasal revestida parcialmente por epitelio escamoso, con un acentuado proceso inflamatorio compuesto de linfocitos, células plasmáticas, eosinófilos y en menor proporción neutrófilos, con presencia de áreas de necrosis. Se observaron abundantes elementos micóticos filiformes,

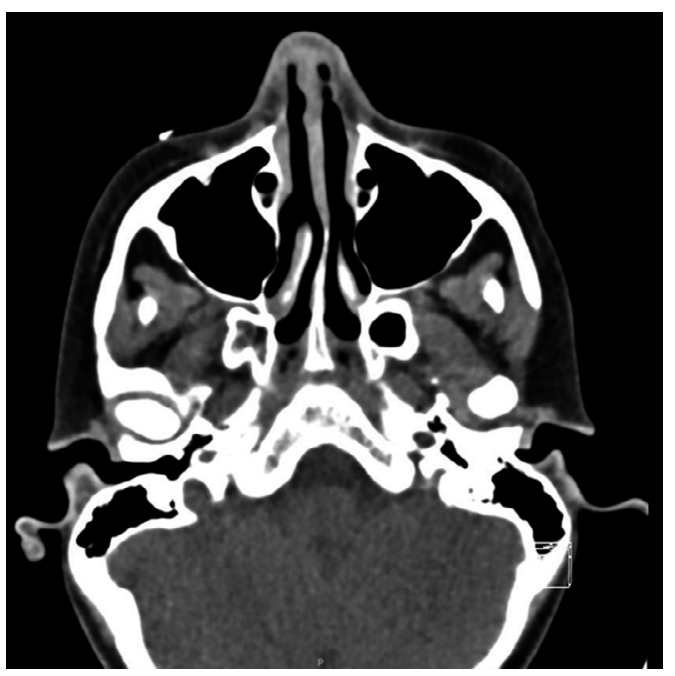

Figura 2. Tomografía computarizada (TC) de cavidades paranasales con leve engrosamiento mucoso en el seno esfenoidal y celdillas etmoidales anteriores a derecha, sin signos de lesión ósea destructiva. 


\section{Caso Clínico}

Dada la similitud morfológica con especies estrecha-

algunos largos, muchos de ellos con tabiques, algunos con ramificaciones en $45^{\circ}$, otros más gruesos y redondeados, positivos a la tinción PAS y Grocott (Figura 3 y 4).

La muestra para cultivo de hongos fue analizada en el Laboratorio de Microbiología del Hospital Dr. Luis Calvo Mackenna, desde donde se derivó para su identificación al Laboratorio de Micología de la Universidad de Valparaíso y al Programa de Microbiología y Micología del Instituto de Ciencias Biomédicas de la Universidad de Chile. En ambos centros, se identificó como Exserohilum rostratum (Figura 5 y 6 ). mente relacionadas se realizó la identificación molecular. La evaluación de las secuencias nucleotídicas estableció como identificación final E. rostratum.

Adicionalmente se evaluó la actividad de anfotericina B y voriconazol, mediante microdilución en caldo siguiendo las normativas del CLSI (CLSI, M-38A-2). Las concentraciones mínimas inhibitorias obtenidas fueron de 0,25 y $0,5 \mu \mathrm{g} / \mathrm{ml}$; respectivamente.

A los seis días de iniciada la terapia antifúngica, y por persistencia de la lesión en el fondo de fosa nasal dere-
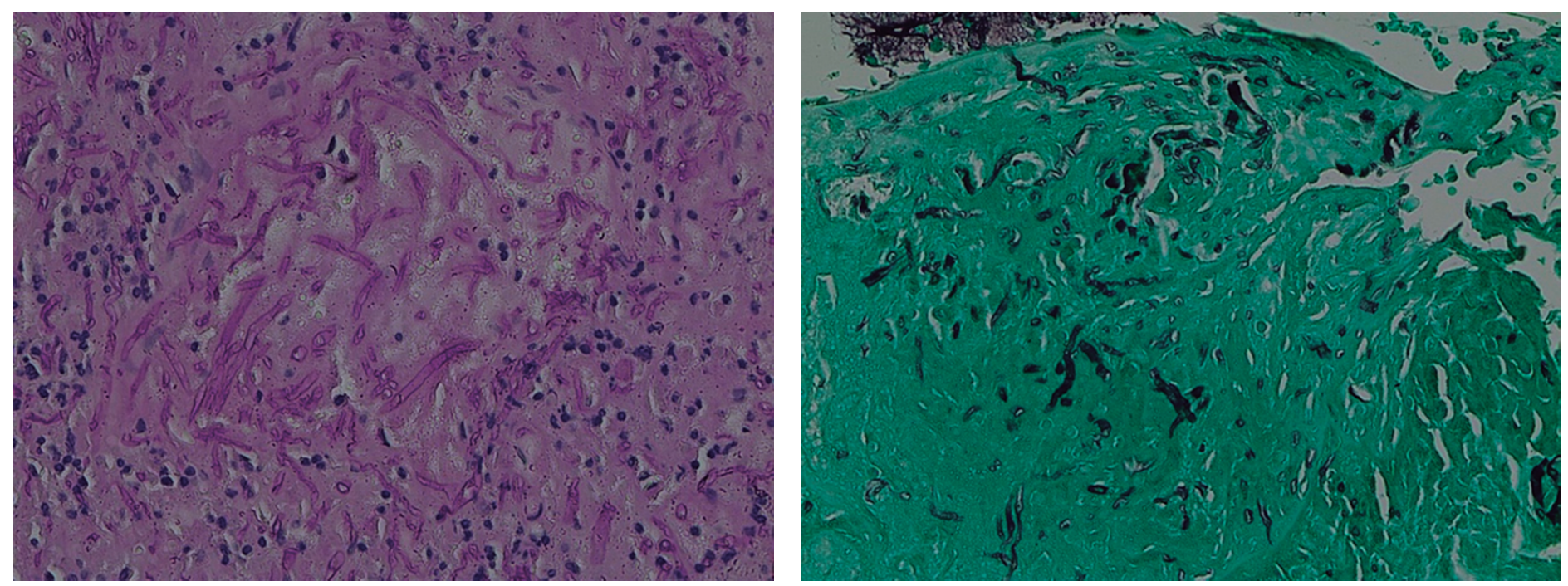

Figuras 3 y 4. Elementos micóticos filiformes, algunos largos, muchos de ellos con tabiques y algunos con ramificaciones en $45^{\circ}$, positivos a la tinción PAS (Figura 3) y Grocott (Figura 4).

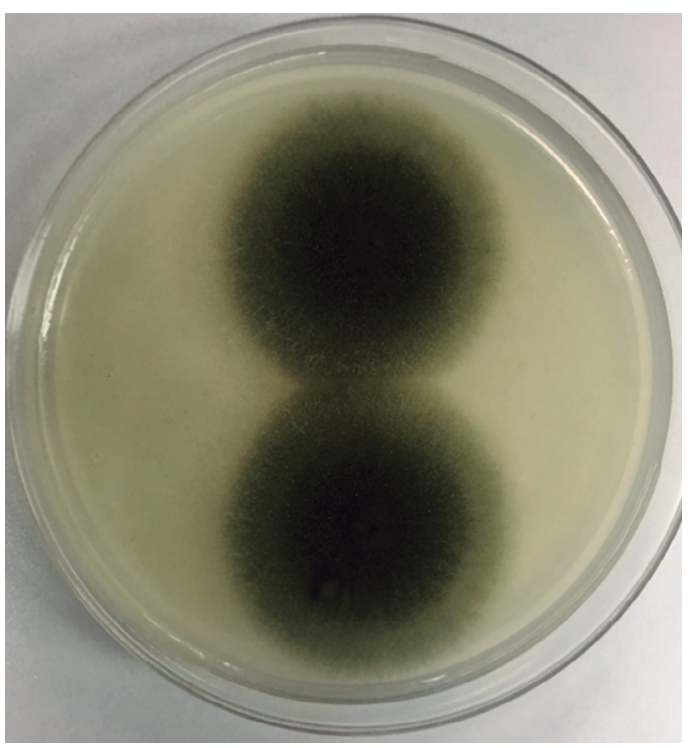

Figura 5. Colonia en agar papa zanahoria a los 5 días de cultivo a $25^{\circ} \mathrm{C}$ y $37^{\circ} \mathrm{C}$, color oliváceo-pardo oscuro.

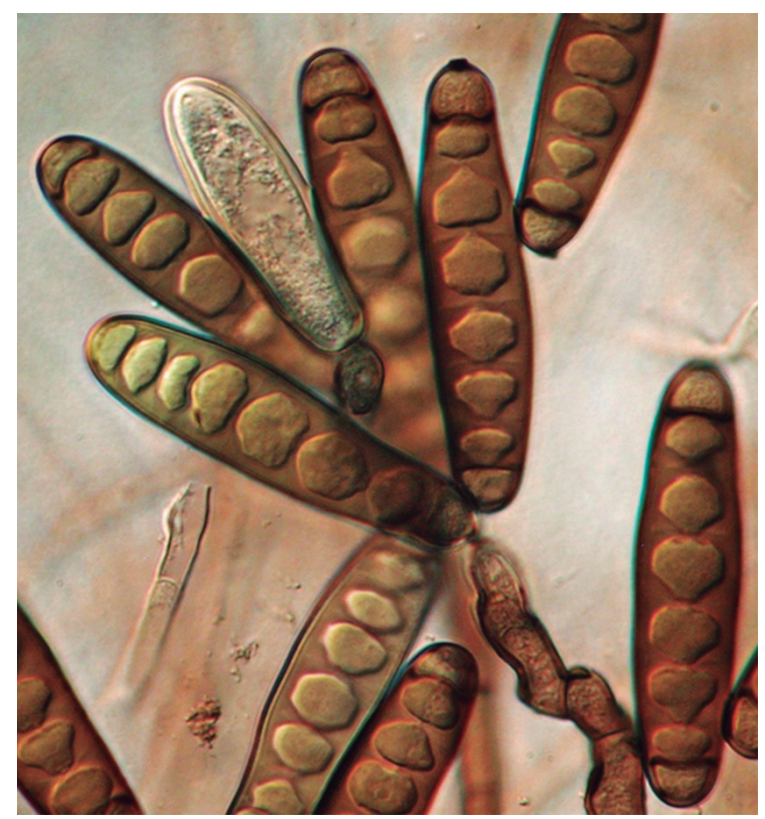

Figura 6. Conidióforos de hasta $230 \mu \mathrm{m}$ de largo, de 5 a $8 \mu \mathrm{m}$ de ancho, erectos a flexuosos, geniculados, de color oliváceo-café y pálidos hacia el ápice. Conidios rectos o ligeramente curvados, rostrados, de paredes lisas, de color oliváceo-café, de 50-128 × 9-23 $\mu \mathrm{m}, 100 \mathrm{X}$. Microscopio DIC. 
cha, se realizó un nuevo aseo quirúrgico que evidenció una lesión costrosa negruzca en septum anterior, la cual se removió. Se apreció además tejido subyacente vital, cartílago expuesto, sin lesiones sospechosas en el resto de ambas fosas nasales. No se tomaron nuevas muestras para cultivo ni biopsia. A los siete días de tratamiento, habiendo descartado una mucormicosis, se ajustó la dosis de anfotericina B liposomal a $3 \mathrm{mg} / \mathrm{kg} / \mathrm{día}$.

El paciente evolucionó favorablemente, afebril, sin dolor, con regresión de la lesión nasal, y con parámetros inflamatorios bajos. Se repitió la TC de cavidades paranasales a los catorce días de iniciado el tratamiento antifúngico que mostró un menor grosor de la mucosa nasal (Figura 7).

Completó catorce días de tratamiento con anfotericina B liposomal y luego se inició profilaxis secundaria con anfotericina $\mathrm{B}$ liposomal en los períodos de neutropenia. A la fecha de este reporte no ha presentado nuevas lesiones.

\section{Discusión}

El género Exserohilum (familia Pleosporaceae, orden Pleosporales) está formado por hongos filamentosos y dematiáceos. Se caracteriza por conidios largos de color negro, multiseptados. De las especies descritas, sólo $E$. rostratum causa infección en el ser humano, siendo la especie causante del brote en E.U.A el año $2012^{4}$.

Nuestro paciente presentó una lesión en la mucosa nasal derecha asociada a fiebre, en el contexto de una neutropenia profunda tras su quimioterapia de inducción, lo que hizo sospechar una EFI. La incidencia de infecciones fúngicas ha aumentado en las últimas décadas, tanto por los tratamientos inmunosupresores utilizados, como por acceso a mejores métodos diagnósticos ${ }^{7}$. Sin embargo, y a pesar de los avances del diagnóstico y manejo, las EFI mantienen una alta tasa de mortalidad, por lo que el diagnóstico oportuno y el inicio precoz de terapia antifúngica se consideran esenciales para la sobrevida de estos pacientes.

Luego de analizar la lesión clínica, la imagen radiológica y de conocer la especie causante -a partir de cultivos de mucosa nasal-, se diagnosticó una infección local rinosinusal por E. rostratum, sin invasión a otros territorios, descartándose una EFI, a pesar de tratarse de un paciente inmunocomprometido. Al momento de su presentación clínica, se planteó como diagnóstico diferencial la posibilidad de otras infecciones fúngicas de presentación rino-sinusal, como aspergilosis y mucormicosis, las que fueron descartadas a través del estudio microbiológico y molecular de este paciente. El niño fue sometido a aseos quirúrgicos en dos oportunidades asociado a la terapia antifúngica con anfotericina liposomal por 14 días, en

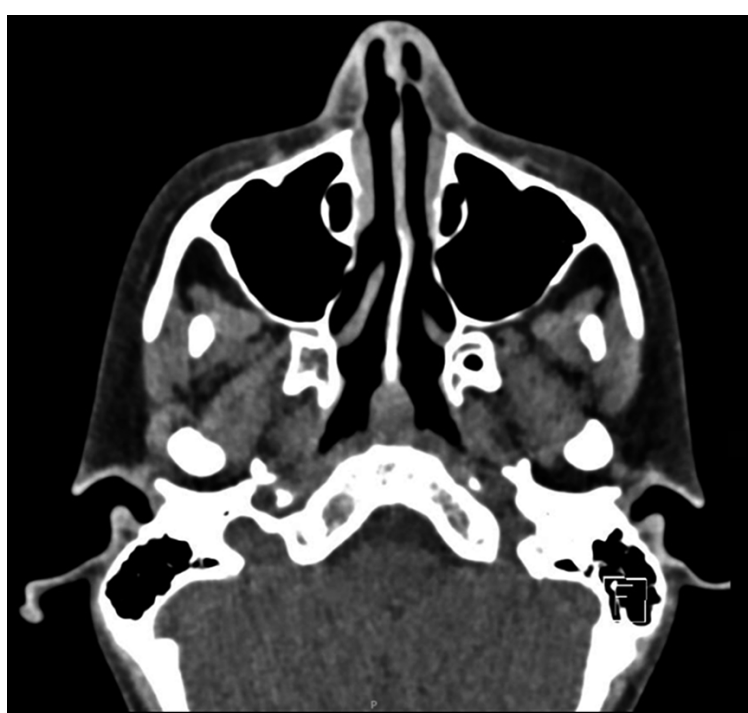

Figura 7. Tomografía computarizada (TC) de cavidades paranasales con leve menor grosor de tejidos blandos del tabique nasal e irregularidad de su contorno, posiblemente cambios post-quirúrgicos, sin reconocer áreas de destrucción ósea que sugieran un proceso infeccioso invasor.

dosis de $5 \mathrm{mg} / \mathrm{kg} /$ día inicial (por sospecha de mucormicosis) y $3 \mathrm{mg} / \mathrm{kg} /$ día posterior, con buena respuesta clínica e imagenológica.

En el brote epidémico en E.U.A. el año 2012, fueron evaluadas 45 cepas de E. rostratum por el Laboratorio de Referencia de los Centros para el Control y Prevención de Enfermedades (CDC por su sigla en inglés). Se estudió la susceptibilidad a anfotericina B liposomal y azoles, dejando fuera a las equinocandinas por su baja actividad sobre hongos filamentosos y dematiáceos. Los resultados mostraron una buena actividad de anfotericina y de azoles, con excepción de fluconazol ${ }^{8}$.

Esta presentación clínica ha sido descrita previamente. En Australia, en una serie de 11 casos pediátricos con cultivo positivo para E. rostratum entre 2003 y 2018, 50\% de ellos tuvieron compromiso rino-sinusal, destacando que esta afección puede ser rápidamente invasora en niños inmunocomprometidos ${ }^{9}$.

Enfatizamos la relevancia de tener una alta sospecha clínica, acompañada de un oportuno estudio diagnóstico y de la realización de un aseo quirúrgico rápido, todo en un plazo no superior a $24 \mathrm{~h}$, lo que se relaciona con el pronóstico de las EFI en niños inmunocomprometidos.

Agradecimientos: A Francisca Valdivieso, Eduardo Álvarez y Rodrigo Cruz, por su gran aporte en la identificación microbiológica que permitió orientar una adecuada terapia para la resolución del caso. 


\section{Caso Clínico}

\section{Referencias bibliográficas:}

1.- Alajmi S, Kotarum R M, Khan Z, Ahmad S, Jeragh A, Ibrahim $\mathrm{H}$, et al. Allergic fungal sinusitis caused by Exserohilum rostratum and literature review. Mycopathologia 2019; 184 : 89-96. doi: 10.1007/s11046-018-0288-z.

2.- Adler A, Yaniv I, Samra Z, Yacobovich J, Fisher S, Avrahami G, et al. Exserohilum: an emerging human pathogen. Eur J Clin Microbiol Infect Dis 2006; 25: 247-53. doi: 10.1007/s10096-006-0093-3.

3.- Saint-Jean M, St-Germain G, Laferrière C, Tapiero B. Hospital-acquired phaeohyphomycosis due to Exserohilum rostratum in a child with leukemia. Can J Infect Dis Med Microbiol 2007; 18: 200-2. doi: $10.1155 / 2007 / 384743$.

4.- Katragkou A, Pana Z D, Perlin D S, Kontoyiannis D P, Walsh T J, Roilides E. Exserohilum infections: review of 48 cases before the 2012 United States outbreak. Med Mycol 2014; 52: 376-86. doi: 10.1093/mmy/ myt030.

5.- Smith R M, Schaefer M K, Kainer M A, Wise M, Finks J, Duwve J, et al. Fungal infections associated with contaminated methylprednisolone injections. N Engl J Med 2013; 369: 1598-609. doi: 10.1056/ NEJMoa1213978.

6.- Astolfo M F, Cañazares P, Majek E, Burgesser V, Caruso M, Basco J, et al. Sinusitis aguda invasiva por Exserohilum rostratum en una paciente pediátrica con recaída medular de leucemia linfoblástica aguda. Arch Argent Pediatr 2018; 116: e594-e598. doi: 10.5546/ aap.2018.e594.

7.- Vallejo J C, Ruiz-Camps I. Infección fúngica invasora en los pacientes hematológicos. Enferm Infecc Microbiol Clin. 2012; 30: 572-9. doi: 10.1016/j.eimc.2012.08.003.

8.- Pappas P G, Kontoyiannis D P, Perfect J R, Chiller T M. Real-time treatment guidelines: considerations during the Exserohilum rostratum outbreak in the United States. Antimicrob Agents Chemother 2013; 57: 15736. doi: 10.1128/AAC.00205-13

9.- Dobinson H C, Down G, Clark J E. Exserohilum infections in Australian Queensland children. Mycoses 2019; 62:181-5. doi: 10.1111/myc.12864. 